\title{
Filosofía y prensa en Colombia: el caso del Magazín Dominical de El Espectador (1980-1990). Una experiencia investigativa*
}

\author{
Damián Pachón Soto \\ Camilo Cuéllar ${ }^{* * *}$
}

\begin{abstract}
ReSUMeN
Recibido: 17 de marzo de 2015

Evaluado: 20 de abril de 2015 Aceptado: 7 de mayo de 2015

Este artículo busca dar respuesta a la siguiente pregunta: ¿sé ocupan los filósofos colombianos de las problemáticas nacionales? Para responderla se acudió al levantamiento de archivo y posterior análisis de los artículos de interés filosófico publicados en Magazín Dominical de El Espectador en 1980-1990. Se partió del supuesto de que es posible encontrar en la prensa escritos filosóficos relacionados con las coyunturas y realidades nacionales de ese convulsivo periodo.
\end{abstract}

Palabras clave: filosofía, prensa, realidad, universidad, educación, paz, violencia.

Artículo de investigación. Proviene del proyecto de Investigación "Filosofía y prensa en Colombia: 1980-2010", realizado por el Grupo de Investigación: "Fray Bartolomé de las Casas". Línea: Estudios sobre Historia del Pensamiento y la Cultura en Colombia y América Latina. El proyecto fue financiado por el FODEIN, Convocatoria 2014. .Cómo citar este artículo: Pachón Soto, D., Cuellar, C. (2015). Filosofía y prensa en Colombia: el caso del Magazín Dominical de El Espectador (1980-1990). Una experiencia investigativa. Hallazgos, 12(24), 177-199 (doi: http://dx.doi.org/10.15332/ s1794-3841.2015.0024.10).

** Magíster en Filosofía, Universidad Santo Tomás (Colombia). Profesor de la Facultad de Filosofía y Letras, Universidad Santo Tomás. Correo electrónico: damianpachon@gmail.com

*** Profesional en Estudios Literarios, Universidad javeriana (Colombia). Investigador de la Facultad de Filosofía y Letras, Universidad Santo Tomás (Colombia) y coordinador editorial, Universidad Cooperativa de Colombia. Correo electrónico: camilo.cuellarm@ucc.edu.co 


\title{
Philosophy and press in Colombia: the case of the El Espectador Magazín Dominical (1980-1990). A research experience
}

\begin{abstract}
This article seeks to answer the following question: do Colombian philosophers look at national problems? For the answer it turned to the collection of archives and subsequent analysis of the articles of philosophical interests published in the El Espectador Magazín Dominical in 1980-1990. It stated for the supposition that it is possible to find philosophical writings in the press related to the national situations and realities of that convulsive period.
\end{abstract} Received: March 17, 2015 Evaluated: April 20, 2015 Accepted: May 7, 2015

Keywords: philosophy, press, reality, university, education, peace, violence. 


\section{Filosofia e imprensa na Colômbia: o caso do Magazin Dominical de El Espectador (1980-1990). Uma experiência investigativa}

Recebido: 17 de março de 2015
Avaliado: 20 de abril de 2015
Aceito: 7 de maio de 2015

\section{Resumo}

Este artigo procura dar resposta à seguinte pergunta: discorrem os filósofos colombianos sobre as problemáticas nacionais? Para respondê-la se consultou o arquivo e se realizou a posterior análise dos artigos de interesse filosófico publicados no Magazín Dominical de El Espectador entre 1980-1990. O ponto de partida foi o suposto de que possível encontrar na imprensa escritos filosóficos relacionados com as conjunturas e realidades nacionais nesse convulsivo período.

Palavras-chave: filosofia, imprensa, realidade, universidade, educação, paz, violência. 


\section{INTRODUCCIÓN}

El 3 de marzo de 2011, el periodista Rodrigo Restrepo publicó en la revista Arcadia del grupo Semana un artículo titulado “¿Dónde están los filósofos?". El artículo iniciaba con un encabezado que decía:

En un país lleno de problemas que necesitan de reflexión profunda, los pensadores colombianos parecen mantenerse distanciados en su torre de marfil. ¿Por qué viven tan alejados del debate público? ¿No ha existido acaso en Colombia una importante tradición de intelectuales públicos? ¿O es que en este tiempo de mass-market los escritores han usurpado el lugar de los filósofos en los medios? (Restrepo, 2011).

Lo que el artículo denunciaba era la poca atención que el filósofo prestaba a los problemas de la realidad nacional, a los temas del día a día, de la coyuntura política, al conflicto, etc. La indignación del articulista llegó hasta plantear la "muerte del filósofo"; si bien aventuró algunas de las razones por las cuales el filósofo se mantenía en esta indiferencia frente a los problemas de su entorno socioeconómico-político, entre ellas el temor a bajarse de nivel y no poder ahondar lo suficiente en los problemas.

Pero, ¿es cierto que los filósofos no se ocupan de los problemas nacionales? En este artículo exploramos las publicaciones filosóficas realizadas en el Magazin Dominical de El Espectador en los años 1980-1990(una década convulsiva en la historia de Colombia), para determinar cuántas de esas publicaciones hacen referencia a las problemáticas coyunturales y a los problemas de la nación en ese mismo periodo; por ejemplo, la violencia, la paz, el narcotráfico, la extradición, el problema de las universidades y su función social, etcétera, o si, efectivamente, el filósofo es ajeno a lo que sucede en su entorno.

En este sentido, se parte del supuesto de que la prensa suele publicar temas de actualidad y, que tal vez, en ese caso, los filósofos plantearon sus inquietudes frente a lo que sucedía a su alrededor. Tal vez así pueda dársele una respuesta a la polémica

\section{EL ARCHIVO Y SU ANÁLISIS}

El estudio de archivo del Magazín Dominical de El Espectador en los años 1980-1990 arrojó 47 artículos de carácter filosófico. Esa selección implicó revisar muchos artículos y descartar aquellos que no se relacionaban con la filosofía ${ }^{4}$. El paso siguiente fue la lectura rigurosa de cada uno de esos 47 artículos, seleccionando aquellos que aludían a las problemáticas del país en lo social, económico, político o cultural. La relación de los 47 artículos se muestra en la tabla 1, donde aquellos que están resaltados con negrilla corresponden a textos que presentan interés filosófico por estar referidos a problemáticas nacionales.

4 Se siguieron básicamente dos criterios: el primero, que el artículo fuera de la autoría de un filósofo; el segundo, que aunque fuera escrito por alguien de otra disciplina, el artículo aludiera a autores o problemáticas clásicas de la filosofía. Estos dos criterios determinaban lo que aquí se ha llamado "de interés filosófico". 
Tabla 1. Artículos de "interés filosófico" publicados en Magazín Dominical de El Espectador (1980-1990)

\begin{tabular}{|c|c|}
\hline Autor & NOMBRE ARTíCULO (EN ORDEN CRONOLÓGICO DESDE 1980-1991) \\
\hline 1. Rubén Jaramillo Vélez. & Sartre una conciencia moral en la política. \\
\hline 2. Rafael Gutiérrez Girardot. & Pidiendo un Ortega desde dentro. \\
\hline 3. Martínez Guarín & "No vamos a tener un Descartes, un Hegel o un Kant". \\
\hline 4. Rafael Gutiérrez Girardot. & La carta de la semana: de Ernesto Cortes Ahumada. \\
\hline 5. Rubén Jaramillo Vélez. & $\begin{array}{l}\text { El ensayo filosófico. Introducción a la lectura del primer capítu- } \\
\text { lo del libro. }\end{array}$ \\
\hline 6. Rubén Jaramillo Vélez. & Divulgación filosófica: ¿Qué es la época moderna? \\
\hline 7. Rubén Jaramillo Vélez. & Divulgación filosófica: Kant y nosotros. \\
\hline 8. Rubén Jaramillo Vélez. & Divulgación filosófica: El último verano de Nietzsche. \\
\hline 9. Rubén Jaramillo Vélez. & La carta de la semana: "el ultra" de Heinrich Mann. \\
\hline 10. Rubén Jaramillo Vélez. & Heinrich Mann: el crítico social. \\
\hline 11. Rubén Jaramillo Vélez. & Aproximación didáctica al expresionismo. \\
\hline 12. Rubén Jaramillo Vélez. & Expresionismo el enfoque conservador. \\
\hline 13. Rubén Jaramillo Vélez. & Ana Freud: 1895-1982. Sustituto y complemento de su padre. \\
\hline 14. Rubén Jaramillo Vélez. & La carta de la semana: Eddy Torres. \\
\hline 15. Guillermo Hoyos Vásquez. & "El poder de la universidad es el poder del saber". \\
\hline 16. Rubén Jaramillo Vélez. & 500 Años de Reforma. \\
\hline 17. Rubén Jaramillo Vélez. & Teología expresionista. \\
\hline 18. Rubén Sierra Mejía. & Acerca de la Filosofía Latinoamericana: lo propio y lo extraño. \\
\hline 19. Guillermo Hoyos Vásquez. & Respuestas democráticas a una universidad en conflicto. \\
\hline 20. Rubén Jaramillo Vélez. & La filosofía y la provincia. Primera parte. \\
\hline 21. Rubén Jaramillo Vélez. & La Filosofía y la provincia. Segunda parte. \\
\hline 22. Ernesto Cortés Ahumada. & Comentario al texto la filosofía y la provincia. \\
\hline 23. Alfonso Gómez Gómez. & Comentario al texto la filosofía y la provincia. \\
\hline 24. Rubén Jaramillo Vélez. & A propósito de Mephisto: el intelectual y el poder. \\
\hline 25. Rubén Jaramillo Vélez. & ¿Qué es la ilustración? Traducción. \\
\hline 26. Guillermo Hoyos Vásquez. & La Universidad Nacional y los procesos de paz. \\
\hline 27. Rubén Jaramillo Vélez. & Kant en Colombia. \\
\hline $\begin{array}{l}\text { 28. Juan Guillermo Gómez, Carlos } \\
\text { Sánchez, José Hernán Castilla } \\
\text { Entrevista con Gutiérrez Girardot. }\end{array}$ & Educación para la mayoría de edad y para la democracia. \\
\hline 29. Leonardo Tovar González. & $\begin{array}{l}\text { A los } 200 \text { años de “¿Qué es la Ilustración?”. La razón pública } \\
\text { hoy. }\end{array}$ \\
\hline 30. Rubén Jaramillo Vélez. & La Banalidad del Mal. \\
\hline 31. Rubén Jaramillo Vélez. & Epílogos: la profundidad del bien. \\
\hline
\end{tabular}




\begin{tabular}{ll}
\hline 32. Rafael Gutiérrez Girardot. & Realidad y heterodoxia en la cultura. \\
\hline 33. Rafael Gutiérrez Girardot. & Universidad y sociedad. \\
\hline 34. Rubén Jaramillo Vélez. & Maquiavelo y la modernidad. \\
\hline 35. Rubén Jaramillo Vélez. & Nota sobre la etiología de la violencia indiscriminada. \\
\hline 36. Guillermo Hoyos (Entrevistador). & $\begin{array}{l}\text { El “mundo de la vida” como fundamento trascendental de } \\
\text { todo conocimiento objetivo. }\end{array}$ \\
\hline 37. Rubén Jaramillo Vélez. & Cultura y barbarie. \\
\hline 38. Rubén Jaramillo Vélez. & La dimensión política del narcisismo. \\
\hline 39. Rubén Jaramillo Vélez. & La inteligencia de la modernidad. \\
\hline 40. Rubén Jaramillo Vélez. & Una carta de Nietzsche. \\
\hline 41. Rubén Jaramillo Vélez (traductor). & Noticia sobre Iwan Goll. \\
\hline 42. Rubén Jaramillo Vélez. & $\begin{array}{l}\text { Breve recuento de los hechos que antecedieron a aquellos de } \\
\text { que propiamente se trata. }\end{array}$ \\
\hline 43. Rafael Gutiérrez Girardot. & $\begin{array}{l}\text { Notas al margen de “El arco y la lira” de Octavio Paz. Primera } \\
\text { Parte. }\end{array}$ \\
\hline 44. Rafael Gutiérrez Girardot. & $\begin{array}{l}\text { Notas al margen de “El arco y la lira” de Octavio Paz. Segunda } \\
\text { Parte. }\end{array}$ \\
\hline 45. Rubén Jaramillo Vélez (traductor). & Marcuse-Heidegger: cartas cruzadas después de la guerra. \\
\hline 46. Rubén Jaramillo Vélez (traductor). & Ocurrencias de Claire Goll. \\
\hline 47. Rubén Jaramillo Vélez. & El trabajo de Nijole. \\
\hline
\end{tabular}

Fuente: elaboración propia.

Esto quiere decir que de los 47 artículos publicados como de carácter filosófico en el suplemento de El Espectador, 17 de ellos están referidos a problemáticas de interés nacional o de la realidad colombiana. En términos porcentuales, estos 17 artículos equivalen a un $36,17 \%$ del total, como se muestra en la figura 1.

Figura 1. Porcentaje de artículos relacionados con realidad nacional

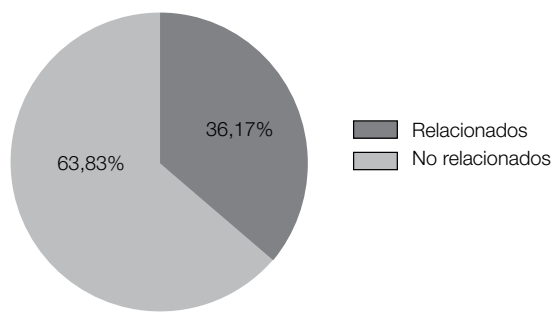

Fuente: elaboración propia.
Por otro lado, se evidenció que el autor que más publicó en la prensa en esa época fue Rubén Jaramillo Vélez, seguido de Rafael Gutiérrez Girardot y Guillermo Hoyos Vásquez. Como es ampliamente sabido en los medios filosóficos colombianos, todos se formaron en la tradición alemana y en el caso de Gutiérrez y Hoyos lograron un notorio reconocimiento internacional. Incluso, Gutiérrez obtuvo en Bonn, Alemania, el título de Profesor Emérito y llegó a publicar varias obras con la editorial más importante del continente: el Fondo de Cultura Económica fundado en los años treinta del siglo pasado por Daniel Cossio Villegas. Gutiérrez fue uno de los críticos de literatura latinoamericanos más importante del siglo XX. Por su parte, Guillermo Hoyos perteneció 
Figura 2. Número de artículos publicados por autor

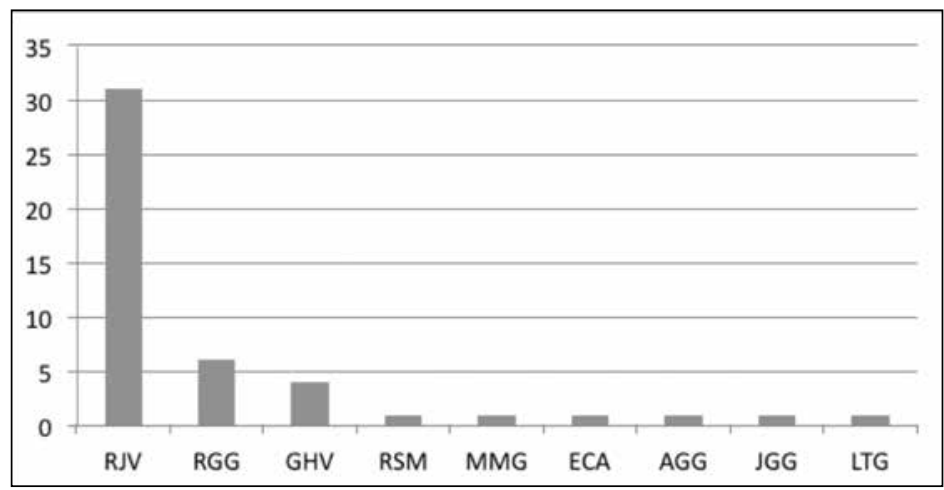

Fuente: elaboración propia.

Nota: RJV: Rubén Jaramillo Vélez; RGG: Rafael Gutiérrez Girardot; GHV: Guillermo Hoyos Vásquez; RSM: Rubén Sierra Mejía; MMG: Mario Martínez Guarín; ECA: Ernesto Cortés Ahumada; AGG: Alfonso Gómez Gómez; JGG: Juan Guillermo Gómez et al.; LTG: Leonardo Tovar González.

Figura 3. Porcentaje de artículos publicados por autor

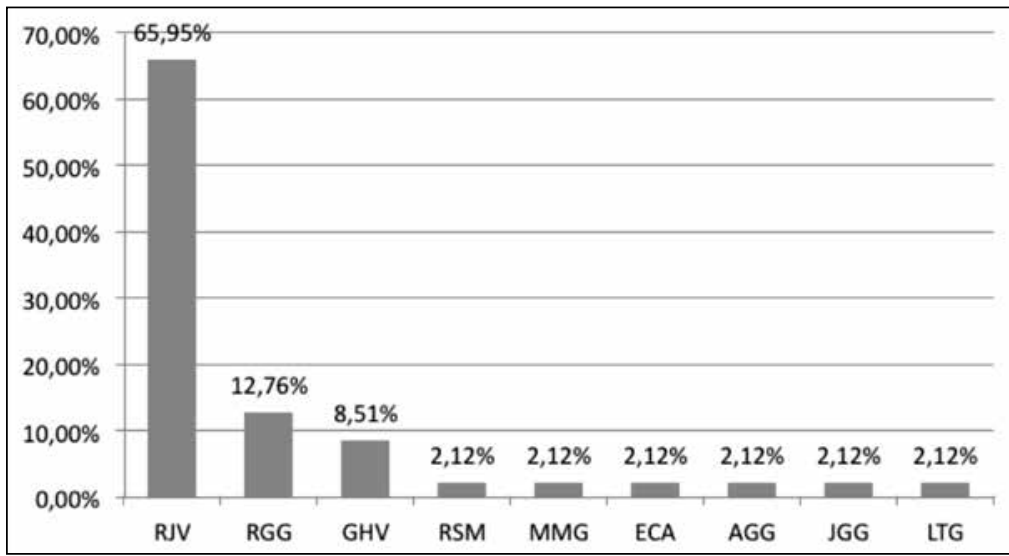

Fuente: elaboración propia.

Nota: RJV: Rubén Jaramillo Vélez; RGG: Rafael Gutiérrez Girardot; GHV: Guillermo Hoyos Vásquez; RSM: Rubén Sierra Mejía; MMG: Mario Martínez Guarín; ECA: Ernesto Cortés Ahumada; AGG: Alfonso Gómez Gómez; JGG: Juan Guillermo Gómez et al.; LTG: Leonardo Tovar González.

a la Enciclopedia Iberoamericana de Filosofía y jugó un rol de filósofo público muy importante en el país. En el caso de Rubén Jaramillo su obra está siendo estudiada en estos momentos y se constituye en una de las más eruditas del país, gracias a su conocimiento de la cultura alemana. Jaramillo Vélez también jugó, con su revista Argumentos, un importante papel como difusor cultural. 
Como se aprecia en la figura 3, el total de artículos (sobre los 47) de Rubén Jaramillo representa el 65,95\%, hecho que lo convierte en el filósofo con mayor presencia en $\mathrm{Ma}$ gazín Dominical. Ahora, en cuanto a los 17 artículos publicados referidos a los problemas nacionales de la época (tabla 1), Jaramillo Vélez aparece con 5 artículos;Guillermo Hoyos, con 4, y Gutiérrez Girardot, con 3. Aquí se mantiene también la preminencia de Jaramillo Vélez.

\section{Análisis cualitativo}

Una lectura de los 17 artículos permite concluir que los filósofos colombianos estuvieron preocupados por los siguientes temas: el problema del papel del intelectual en la realidad colombiana, el problema de la existencia de una filosofía latinoamericana, así como del proceso del surgimiento de la filosofía colombiana; la crítica de nuestra situación cultural y su relación con la herencia española, la preocupación por la universidad y la educación. En este último caso, lo curioso es que Kant, ya fuera por los doscientos años de publicada la Crítica de la razón pura (1781) o los doscientos años de su célebre texto Respuesta a la pregunta ¿qué es la Ilustración?,sirvió de hilo conductor para reflexionar sobre nuestra situación cultural y educativa. Así mismo, hay una alusión al problema de la violencia (Jaramillo, 1986) ${ }^{5}$, así como al problema de la relación entre universidad y paz.

5 El artículo de Rubén Jaramillo titulado "Nota sobre la etiología de la violencia indiscriminada" se refiere a la masacre en el restaurante de Pozzeto, ocurrida en Bogotá en 1986. Sin embargo, otros artículos aluden más precisamente a la violencia social colombiana. Aquí el comentario es marginal y más erudito como es la costumbre del autor, más interesado en difundir la cultura alemana entre nosotros. El artículo fue publicado el 21 de diciembre de 1986.

\section{El intelectual frente a la realidad}

Tras la muerte de Sartre ocurrida en 1980, el Magazín Dominical de El Espectador publicó el artículo "Sartre: una conciencia moral en la política" de Rubén Jaramillo Vélez (publicado el 20 de abril de 1980). La intención era clara: no se trataba de una mera nota necrológica, sino además de resaltar el papel que Sartre había tenido en las múltiples intervenciones públicas y de su talante crítico en la sociedad francesa. En efecto, la crítica es asumida como deber moral del intelectual frente a lo que sucede a su alrededor, no solo por lo que denuncia o esclarece, sino también por las salidas que pueda vislumbrar, a pesar o no de sus respectivos errores políticos. Nos dice Jaramillo (1980): "Sartre no se limitó a ser un testigo de su época. Trató de asumir una vocación moral: ser, también, la conciencia - la mala conciencia- de su tiempo" (p. 5). Resaltando, igualmente, la postura de Sartre frente a la guerra de Vietnam:

[...] como portavoz de quienes en Europa se sentían solidarios con el pueblo vietnamita, participó en aquellas acciones que a partir del año 65 lograron aglutinar a la juventud, los intelectuales, los científicos humanistas, en contra del genocidio que se practicaba a diario por la más poderosa tecnología militar jamás conocida, en los campos de Vietnam. La erección del tribunal Rusell para juzgar los crímenes de guerra cometidos por el agresor fue el punto culminante de la campaña (p. 5).

Esto para decir que en la situación colombiana del momento (recordemos las violaciones a los derechos humanos en el gobierno Turbay): 
Tal vez resulte necesario recordarlo hoy, cuando la reflexión ética sobre la política se ve cada día más y más remplazada por el ejercicio de la banalidad de los politólogos, que parecen haber asumido una función específica del lenguaje unidimensional: eliminar la conciencia desgraciada, la mala conciencia. Tal vez sea necesario recordarlo aquí y ahora en este país sobre el cual pende un interrogante universal; porque todos los hombres decentes se preguntan cómo, cuándo, dónde, a quién, a quiénes se ha torturado (Jaramillo, 1980, p. 5).

El artículo de Jaramillo Vélez no solo llama al intelectual a que sea una conciencia crítica de su tiempo, o en sus palabras "una mala conciencia", sino que de paso lanza una crítica a la "ciencia política", a los politólogos, por contribuir, de hecho, con su saber tecnocrático (a eso se alude con la referencia indirecta a Marcuse) a eliminar esa "mala conciencia" de la sociedad. Y Sartre, entonces, no solo es ejemplo de esa moralidad del intelectual; también hace falta en una sociedad como la colombiana (la de los años ochenta) esclarecer lo que ha pasado, "cómo, cuándo, dónde, a quién, a quiénes se ha torturado", en el Gobierno autoritario regido por el "estatuto de seguridad".

Por otro lado, en la entrevista titulada “Educación para la mayoría de edad. Diálogo con Rafael Gutiérrez Girardot" (publicada el 17 de enero de 1988), con respecto a la pregunta del papel del intelectual para superar el dogmatismo legado por la tradición hispánica, el crítico de literatura y filósofo residente en Alemania, pero cercano siempre a los sucesos colombianos, aludía a esa necesaria relación del intelectual con su realidad: "La inteligencia no está nunca en el aire, pues una inteligencia que esté en el aire es un juego en sí mismo, sin posibilidad de penetración, es una paradoja, una negación de sí misma". De ahí que:

El intelectual, ya lo había dicho Henríquez Ureña en un ensayo sobre la exuberancia en América, que tiene, digamos, eros intelectual, tiene una raigambre nacional. De modo que el intelectual no tiene por qué sentirse extraño a su sociedad, él pertenece a esa sociedad y aunque la sociedad se sienta incómoda por lo que hace, nadie le puede negar a un [José Luis] Romero, a un [Domingo Faustino] Sarmiento (que me parece un caso arquetípico) que esté arraigado en la sociedad (p. 7).

A lo que apuntaba Gutiérrez era, pues, a tres cosas fundamentales: la primera, al latinoamericanismo del intelectual, a su raigambre; la segunda, a la necesidad de que el intelectual fuera universal, que conociera a la vez su mundo y el resto del mundo, como lo ejemplificaban en América Latina las obras de Alfonso Reyes, Pedro Henríquez Ureña, Sarmiento, José Luis Romero, entre otros; y tercero, que ese intelectual tuviera ethos, esto es, que supiera cómo investigar, escribir libros, dominar las técnicas o, en pocas palabras, que supiera hacer "trabajo de taller", lo cual era muestra fehaciente de su autenticidad como intelectual y del rol que jugaba en la sociedad (Gutiérrez, 1988, pp. 3-9).

\section{Reflexiones en torno a la filosofía latinoamericana y colombiana}

En los años ochenta, Magazín Dominical de El Espectador publicó varios artículos 
referidos al problema de la existencia o no de una filosofía latinoamericana. También dedicó varias páginas al llamado proceso de normalización de la filosofía en Colombia, entendido como el clima apto que favoreció el surgimiento del pensar moderno en Colombia en los años cuarenta del siglo pasado. Al primer asunto se alude en los artículos "No vamos a tener un Descartes, un Hegel o un Kant" de Mario Martínez Guarín; "Acerca de la Filosofía Latinoamericana: lo propio y lo extraño" de Rubén Sierra Mejía, y en la entrevista a Rafael Gutiérrez Girardot titulada "Realidad y heterodoxia de la cultura". Al segundo, los dos artículos de Rubén Jaramillo Vélez sobre "La filosofía y la provincia", las dos cartas de lectores en torno a esos artículos y el artículo de Gutiérrez Girardot, ya citado, "Educación para la mayoría de edad".

Lo importante de este cúmulo de artículos en torno a la filosofía colombiana y latinoamericana es que se reflexiona acerca de la filosofía como parte fundamental y constitutiva de la cultura, como el arte o la literatura. Se la asume como parte del acervo cultural de un país, que tiene su historia, sus antecedentes, sus problemáticas propias. Pero yendo más allá de eso, también porque implica reflexionar sobre un saber disciplinar que precisamente tiene que pensar la realidad colombiana. Es decir, la reflexión, la crítica, la revisión de nuestro pasado filosófico, de los problemas de la disciplina misma se convierten en condición de posibilidad de cualquier reflexión ulterior sobre los problemas nacionales mismos.

El artículo de Mario Martínez Guarín es una sinopsis del I Congreso Internacional de Filosofía Latinoamericana organizado por la
Universidad Santo Tomás en 1980. Con ese congreso justamente esta universidad abrió un espacio público bianual con grandes invitados internacionales, donde se discutía no solo de la filosofía latinoamericana misma, sino también de múltiples problemas de la sociedad contemporánea. El título del artículo, "No vamos a tener un Descartes, un Hegel o un Kant" (publicado el 3 de agosto de 1980), alude a la intervención del filósofo mexicano Leopoldo Zea, para quien todo saber es situado y la universalidad de la filosofía depende del grado como logre profundizar en una circunstancia específica; de tal manera que no se trata de tener un Descartes, un Kant o un Hegel, porque esos pensadores hicieron sus sistemas filosóficos en otro momento histórico, con contextos y realidades propias de las cuales ellos partieron. Decía Zea:

Se han malentendido los motivos del filosofar latinoamericano; este no pretende imitar, ser eco y sombra de un determinado filosofar; lo único que se propone es reflexionar sobre los problemas de su propia realidad, y para ello se sirve de los mismos instrumentos de los que se sirve el filosofar europeo cuando reflexiona sobre su propia realidad. Lo que va ahora a quedar en duda es si este instrumental eficaz para resolver los problemas de la realidad europea podrá igualmente servir para resolver los problemas de la realidad latinoamericana...Un filosofar sobre los obstáculos con los cuales los hombres de esta América han tropezado, es un filosofar tan auténtico como cualquiera otro: ¿o es que el filosofar no surge frente a una problemática que ha de ser resuelta a veces con gran urgencia? 
¿No es filosófico el reflexionar sobre el cambio que ponga fin a las relaciones de dependencia en que este hombre ha vivido a lo largo de su historia? ¿No es filosófico plantearse el problema de la liberación frente a la dominación y el coloniaje vividos? Obviamente tal filosofar no será semejante al originado en Europa... Un legítimo reflexionar filosófico es el que los latinoamericanos hagan sobre los problemas de su realidad; como legítimo han sido y es, el que se han planteado y se plantean los filósofos occidentales sobre su realidad y sus problemas (citado por Martínez, 1980).

Así las cosas, para el filósofo mexicano era clara le necesidad de una filosofía latinoamericana de la liberación.

Sobre el problema de la filosofía latinoamericana se volvió a preguntar el filósofo Rubén Sierra Mejía en su artículo "Acerca de la Filosofía Latinoamericana: lo propio y lo extraño"(publicado el 15 de enero de 1984). En este artículo, incluido luego en su libro Ensayos impopulares (2002, pp. 3545), el profesor de la Universidad Nacional alude a la "poca creatividad" y aportes que ha mostrado la filosofía misma en el continente y al confuso problema de plantear una "filosofía latinoamericana" como un pensamiento original, propio, determinado por la relación de dependencia y por problemas sociopolíticos. Para Sierra, "es la expresión de una inseguridad en nuestro destino histórico, de una desorientación espiritual de nuestros pueblos, el no querer reconocernos como ciudadanos de la cultura occidental: esa desorientación conduce a buscar nuestra identidad en lo propio" (p. 39). La filosofía de este continente alcanzará la universalidad no por aludir a problemas propios, sino por un "sistema metodológico y de conceptos". Por eso la filosofía latinoamericana debe reconocerse heredera de la filosofía occidental, la cual nació con los griegos. Solo habrá filosofía original en este continente cuando se haga un aporte significativo a esa tradición filosófica, hecho que exige una superación de obstáculos que impiden una "naturalización" de esa filosofía, esto es, que haga parte de nuestra tradición cultural (p. 44).

Como puede verse, en este caso, la posición de Sierra se distancia de la de Leopoldo Zea, pues mientras el primero cree en una auténtica filosofía latinoamericana, que no sea eco de Europa y que sea producto de nuestras propias circunstancias, Sierra se mantiene en la llamada posición "universalista", donde solo es filosofía aquella que alcance por su profundidad y expresión a dar cuenta de los problemas generales del hombre.

Por su parte, Rafael Gutiérrez Girardot, en su texto "Realidad y heterodoxia de la cultura" (entrevista publicada el 29 de septiembre de 1985), aportó frente a este problema una interesante respuesta que citamos in extenso:

En su opinión, profesor Gutiérrez Girardot, ¿considera validadas las expresiones "filosofía latinoamericana"?

Antes de hablar de una filosofía latinoamericana es preciso poder hablar de una filosofía en Latinoamérica. Y para esto faltan las condiciones universitarias en el sentido más amplio del término. Falta, en primer lugar, la formación humanística esto es, la enseñanza adecuada del griego y del latín 
que permite a los estudiantes trabajar en seminarios con textos originales, base indispensable no sólo de la disciplina del pensamiento. Falta, en segundo lugar, la enseñanza del alemán, del inglés y del francés e italiano, que permita a los estudiantes trabajar con textos originales y leer las revistas que difunden nuevos planteamientos. Sin esta condición, la filosofía como tal resulta imposible, pues la filosofía vive hoy más que antes del intercambio de diversas corrientes y opiniones y planteamientos. Sin conocer lo que se hace en la metrópolis tradicional de la filosofía, sin estar al tanto de la marcha del pensamiento, la filosofía que se haga en Colombia, por ejemplo, está condenada fatalmente a improductividad y a un cierto anacronismo.

Falta, igualmente, lo que Francisco Romero llamo la normalidad filosófica, esto es, una atmósfera social favorable a los estudios filosóficos. Ello no significa que Colombia no haya personas que se dediquen con seriedad y pasión a la filosofía, pero si ellas contaran al menos con la normalidad filosófica y con la posibilidad de una información amplia y al día, con una hemeroteca al menos y con bibliotecas, que adquiera regularmente los libros más importantes, es seguro que podría comenzarse a hablar de una filosofía latinoamericana, es decir, de una filosofía que se caracteriza como tal por los acentos que sepa poner la creatividad al pensamiento. Pero lo que falta fundamentalmente es acabar con la calatería que difundió con gracia, arrogancia y donaire de torero Ortega y Gasset, y que ha enseñado a ejercer un pensamiento prologal, por así decir, una bomba de jabón que anuncia algo grande y que nunca llega y nunca se cumple. Esa charlatanería enseñó a incurrir en la intimidación por medio de la bibliografía y del autobombo importantista, como el caso de Lorite Mena.

Por eso para Gutiérrez se podía hablar mejor de un pensamiento latinoamericano, como el de Bello o Rodó, que fundaron las bases de la universidad latinoamericana, pero en cuanto a la filosofía latinoamericana uno de los pasos necesarios era superar el complejo de inferioridad y reconocer la propia tradición intelectual:

Gracias a semejante complejo de inferioridad no [se] ha sabido valorar y continuar lo que dijeron Bello y Rodó. Y sin continuidad, no hay ciencia y menos aún una filosofía "latinoamericana" o una política "latinoamericana" o una cultura "latinoamericana". ¿Cómo pude haberla, si se olvida su propia tradición? (Gutiérrez, 1985, pp. 6-10).

Además de lo dicho anteriormente, el problema de la filosofía latinoamericana tiene que pasar por una reforma de la universidad (a lo que se aludirá más adelante), pero especialmente por una superación de la herencia cultural española. En la entrevista titulada "Educación para la mayoría de edad..." (Gutiérrez, 1988), le preguntaron a Gutiérrez: “¿usted qué relación establecería entre ese catolicismo militante y contrarreformista y en general la actitud filosófica en nuestros países?". A lo que respondió:

Es muy clara. El catolicismo por principio no puede aceptar la discusión filosófica. Esta es una vieja polémica 
a la que se han enfrentado en Europa muy diversamente y de manera muy digna y sutil, entre otros, un gran filósofo católico, Karl Rahner, discípulo de Heidegger. En nuestro país no se ha planteado el problema porque no se ha llegado a pensar que el catolicismo sea problema. Digamos, no se ha planteado desde el punto de vista sociológico. La sociología colombiana igual que la latinoamericana carece de estudios de sociología de las religiones que iluminen este problema. La sociología latinoamericana no se ha planteado el problema del catolicismo como un fenómeno social. Entonces, no cabe esperar que la filosofía se plantee el problema del catolicismo como un problema que le incumbe fundamentalmente.

El catolicismo que trajo España fue identificado con la Nación misma. Desde entonces ese catolicismo ha producido dos problemas, por así decir: el problema de que el pensamiento ha sido visceralmente dogmático y de ahí la dificultad de los pueblos hispánicos no sólo de comprender sino de concebir o de recibir o de aceptar cualquier pensamiento diferente, diferenciado, crítico. Sin dificultad se pasa de Kant a la moda de Hegel, del neohegelianismo al marxismo, de éste al estructuralismo. Esto es comprobable y ese es el primer problema del catolicismo frente a los estudios filosóficos. El segundo problema de ese catolicismo visceral es, naturalmente, el de que no se le puede poner en tela de juicio, porque precisamente forma parte del hábito diario del pensar, de una forma de ver el mundo, algo que se impone y que ha comprometido el comportamiento de la inteligencia, el comportamiento político y social. De modo que se puede ver o suponer que el cuestionamiento del catolicismo desde la sociología o desde la filosofía puede equivaler instintivamente al cuestionamiento de sí mismo. Lo que implica, en última instancia, una cadena, o sea, que al hablar de una sociedad atomizadora y egoísta se puede hablar de una sociedad encerrada en sí misma (pp. 3-9).

Hay que decir que la crítica de Gutiérrez (y de Jaramillo Vélez) a la cultura heredada de España, la cual también es responsable de nuestra insolidaridad y violencia, está basada en la contraposición entre Reforma y contrarreforma. Habermas (2010) lo ha resumido muy bien:

\section{[...] los acontecimientos históricos} clave para la implantación del principio de la subjetividad son la Reforma, la Ilustración y la Revolución Francesa [...] Contra la fe de la autoridad de la predicación y de la tradición el protestantismo afirma la soberanía de un sujeto que reclama insistentemente la capacidad de atenerse a sus propias intelecciones: la hostia sólo puede considerarse ya como masa de harina y las reliquias sólo como huesos (p. 28).

El catolicismo contrarreformista ahogó la crítica, la libertad individual, la capacidad de pensar por sí mismo y sometió al individuo a la autoridad de la fe y de la tradición. En pocas palabras, postergó la modernidad (Jaramillo, 1998).

En cuanto al proceso de normalización en Colombia, este fue abordado por Rubén 
Jaramillo Vélez en los ensayos anteriormente mencionados (1984a y 1984b) ${ }^{6}$. Estos artículos fueron incluidos recientemente en la Revista Aquelarre. Aquí se cita esta última versión. En ellos Jaramillo trata de explicar que el proceso de normalización de la filosofía colombiana o, lo que es lo mismo, el ingreso de la filosofía moderna en el país se debió a la labor de intelectuales, pioneros, provenientes de la provincia y no de la capital. Se refiere específicamente a Danilo Cruz Vélez, Rafael Carrillo, Luis Eduardo Nieto Arteta, Cayetano Betancur. ¿Por qué el interés de la filosofía se da en estos provincianos y no en una generación residente en la capital, en la llamada "Atenas suramericana", como la llamó el filólogo español Marcelino Menéndez y Pelayo? Jaramillo se sumerge en una explicación convincente aludiendo a los efectos que tuvo la Regeneración en la educación y la cultura, lo cual retrasó el surgir de la filosofía entre nosotros. A su vez, atribuye esa extraña circunstancia al hecho de que la provincia estaba más conectada con el mundo capitalista. Y esa conexión siempre favoreció más, como en el caso de México y Argentina, el desarrollo intelectual y filosófico (Jaramillo, 2013a, p. 206).

En fin, el neotomismo de Balmes, Mercier y Rafael María Carrasquilla imperante en la hegemonía conservadora, la cultura de viñeta de Bogotá, sus clases señoriales y pactas, pero también el hecho de que en Colombia no se dio una inmigración semejante a como se dio en México y Argentina, postergaron el ingreso de la modernidad filosófica al país. Esto solo cambia después de los años veinte con el proceso de

6 Los dos artículos titulados "La filosofía y la provincia" se publicaron el 24 de junio y el 1 de julio de 1984, respectivamente. modernización, urbanización, industrialización, el conflicto social, etc., que posibilita esa generación modernizadora (2013b, p. 215), la cual provenía toda - o casi la mayoría- de las disciplinas jurídicas.

La conclusión de los dos artículos podría ser la siguiente: en efecto, el interés por la filosofía nació en esa generación normalizadora en la provincia. No pudo nacer en Bogotá por los efectos retardatarios y antimodernos de la Regeneración. Sin embargo, la institucionalización de la filosofía moderna, la fundación de su primer Facultad, la de la Universidad Nacional creada en 1945, solo fue posible en Bogotá luego de la modernización y sus efectos, así como la política educativa de Alfonso López Pumarejo que le quitó el monopolio educativo a la Iglesia.

Frente a esta interpretación, se pronunciaron dos lectores en el mismo año, en cartas que el periódico publicó. La primera, de Alfonso Gómez Gómez, en la cual no entra a cuestionar los argumentos dados por Jaramillo, pero sí pretende descalificar su sobrada solvencia en estos temas filosóficos (publicada el 29 de julio de 1984).La segunda, titulada,igual que la anterior, "Comentario al texto La filosofía y la provincia", de Ernesto Cortés Ahumada, es un poco más sustancial (publicada el 15 de julio de 1984). Allí sostiene:

[...] el ensayo de Jaramillo es vago, y que lo es además cuando nos deja sin saber en qué consiste la "filosofía colombiana" y cuáles han sido "los caminos recorridos". En efecto: dicho profesor se limita a describirnos las circunstancias que la han hecho posible, deformando - como acabamos de ver - no pocas de ellas y echando 
mano de una especie de "principio de intermediación": Cayetano Betancur (t) nació en Copacabana; Nieto Arteta, en Barranquilla, etcétera. Esta oriundez geográfica, y aparte, claro está, del orgullo del solar nativo, no significa, en filosofía, casi nada, y sobre todo como el profesor Jaramillo nos lo plantea. Puesto que trata a cada filósofo como si fuese una realidad aislada, abs-trac$t a$; o dicho en otra forma: ¿cómo es que los filósofos lograron cohesionar una "filosofía colombiana"? Jaramillo olvida las "largas cadenas de razones" de que habla Descartes, y por eso el lector de su ensayo se quedó en el Limbo, en el Limbo filosófico que es mucho peor que el cristiano. ¡Paraíso de los que demuestran por señas! (p. 1).

Frente a este debate se ha escrito mucho en Colombia. Algunos ya rechazan el concepto de normalización por eurocéntrico, otros lo mantienen pero resemantizado, incluyendo la enseñanza de la filosofía latinoamericana como parte necesaria - y aún inconclusa del mismo. Es más, la categoría puede ser concebida como parte de la "sociología del saber" o de una "historia social de la filosofía" en Colombia, que explique la producción, la circulación, y el consumo de la filosofía (cfr. Pachón, 2015, pp. 283-285).

\section{Universidad, educación y paz}

Uno de los filósofos más conocidos en Colombia, fallecido apenas hace dos años, Guillermo Hoyos Vásquez, dedicó en 1983 y 1984 tres interesantes artículos para reflexionar en torno al papel de la universidad pública y el país. En el primero, sugestivamente titulado "El poder de la universidad es el poder del saber" (publicado el 3 de julio de 1983), sostenía: “La Universidad tiene que estarabierta a la plenaactualidad; más aún: tiene que estar en medio de ella, sumergidaen ella" (1983, p. 5). El artículo es una reflexión sobre el papel de la universidad en la sociedad. Para el profesor Hoyos se trataba de pensar la universidad y sus procesos "de democratización, descentralización y diferenciación de la educación superior", siempre con miras a superar una concepción del pasado en la cual la autonomía universitaria se entendía ya fuera como aislamiento de la sociedad o como militancia.

En este sentido, se debe entender el papel que juega la universidad en la formación profesional, en la economía y en la cultura nacional, razón por la cual el Gobierno no puede desentenderse de ella y abandonar sus responsabilidades con la educación pública. Por eso afirma Hoyos: "El aporte sustantivo de la universidad autónoma y crítica a la democracia y por tanto a la paz y a la libertad, exige no ahorrar ningún esfuerzo por fortalecerla y desarrollarla para bien de todos los colombianos". Eso implica que la sociedad y sus diferentes sectores sean conscientes del papel y la función social de la universidad. ¿Cuáles son esas funciones? La respuesta es evidente:

La universidad forma profesionales que puedan en el sector público o privado cumplir tareas en beneficio de la comunidad; también la universidad entrega conocimientos importantes en el ámbito de la ciencia y de la técnica, que sirven para impulsar el desarrollo del país; finalmente, y esta es una tarea prioritaria y sustantiva de la universidad. Ella está llamada a mantener en la sociedad vivo el interés por la verdad, por la democracia, por la crítica, por las necesidades 
reales del pueblo y por las libertades políticas y la independencia cultural de la Nación. Por ello la universidad tiene que ser en cierta forma cuerpo pensante y alma inspiradora de cultura en el contexto nacional (Hoyos, p. 6)

No se trata solo de la universidad concebida para formar profesionales; se trata de una universidad que abandere la formación integral de los ciudadanos. $\mathrm{Y}$ esto quiere decir que la universidad no debe oponerse a la necesidad de los avances científico-técnicos; todo lo contrario, debe promoverlos, pues esto aumenta la productividad del país. Pero lo que no puede hacer es promoverlos de manera acrítica, eliminando la capacidad reflexiva del estudiante sobre la estructura social y los efectos nocivos de una concepción unilateral de los avances productivos. Si la universidad forma profesionales críticos, estos estarán en capacidad de formular responsablemente alternativas a los problemas sociales. Se trata, pues, de la unión de crítica y responsabilidad con la sociedad, sin someterse meramente al criterio instrumental de la productividad, pues ese criterio lleva a la administración total de la sociedad en desmedro de otras facultades humanas y de la cultura.

Como puede verse, la reflexión de Hoyos está sustentada en el análisis social que realizó la Escuela de Frankfurt desde la primera mitad del siglo $X X$, pero superando ese pesimismo en las reflexiones de Habermas y de las críticas de Husserl al positivismo:

El poder del saber se genera y se legitimaen la posibilidad de convencer al

7 Guillermo Hoyos también publicó una entrevista en este sentido titulada "El mundo de la vida como fundamento trascendental de todo conocimiento objetivo", publicada el 15 de marzo de 1987. otro o de ser convencido por él mediante eldiscurso reflexivo y crítico. En esteproceso discursivo de proponente yoponente, que es de la esencia misma dela democracia, se conserva lo mejor delmétodo para encontrar la verdad en susentido más complejo con relación a losocial, a la política y a la historia (Hoyos, p. 7).

Ese diálogo es el principio de una universidad democrática de cara al país, una universidad que no debe ser mirada simplemente con criterios financieros y cuantitativos, lo cual no hace sino alimentar el llamado a su autofinanciación y, por ende, a su privatización.

En su artículo "Respuestas democráticas a una universidad en conflicto" (publicado el 17 de junio de 1984), Hoyos hace una reflexión sobre el sentido de la universidad, sobre una especie de "filosofía de la educación" basándose, desde luego, en Habermas: "Supunto de partida es un voto de confianza en la razón, en las posibilidades de la persuasión y del discurso, en el poder delas ideas y en la democracia real, tiene que ser el enriquecimiento dela libertad" (1984a, p. 5 y ss.).

Hoyos pasa a referirse al papel emancipatorio de la filosofía y la ciencia, ya en Grecia, ya en la modernidad, y sostiene que la universidad debe, precisamente, equilibrar ese dominio de las fuerzas naturales con los deberes éticos y políticos de la sociedad. En eso consiste la mayoría de edad kantiana. Por eso debe tenerse en cuenta que:
$\mathrm{Al}$ reconocer la función liberadora de la ciencia y la técnica por cuanto amplían indefinidamente las potencialidades 
productivas del hombre, hay que advertir al mismo tiempo que sus posibilidades fascinantes pueden desviarse hacia un modelo de progreso unilateral al margen o inclusive contra de la libertad de la persona. Lo que constituye el más valioso potencial objetivo de liberación, mal interpretado y manipulado, puede ahogar y sofocar las fuerzas subjetivas y los auténticos ideales de emancipación.

Ahora, ¿cuál es la manera de evitar esa perversión de la ciencia y la técnica? Para Hoyos es el poder del lenguaje, una ética comunicativa que democratice la universidad: "Este es el principio de una ética comunicativa, cuya tarea primordial es reconstruir las condiciones objetivas y subjetivas del diálogo, del reconocimiento mutuo y de la interacción social, para asumir democráticamente acciones por mejor calidad de la vida y más libertad".

Y la democracia deliberativa fundamentada en esa ética de la comunicación es fundamental para el logro de la paz.

En el artículo de 1984, Hoyos alude específicamente al problema de la paz y habla de la necesidad de unos marcos que superen el dogmatismo, que lleven al establecimiento de las condiciones objetivas y subjetivas de entendimiento para "superar" el estado en el que se encuentra el país. No hay que olvidar que el contexto de esta reflexión es el papel de la universidad pública, de la educación en la situación de conflicto de la sociedad colombiana de la época y en el proceso de paz que adelantaba el Gobierno de Betancur.

Su siguiente artículo en Magazín Dominical, titulado "La Universidad Nacional y los procesos de paz" (publicado el 14 de octubre de 1984), inicia citando el opúsculo de Kant titulado La paz perpetua. Se resalta la idea de que la paz es un ideal y un compromiso que da sentido a la acción, así la paz no sea un estado alcanzable. De ahí que no se puede esperar una paz como solución de todos los conflictos o, en pocas palabras, concebir la paz como un estado acabado, definitivo. Esto implica la participación de la sociedad en la construcción de los procesos históricos. Aquí todos tienen su parte, en vez de claudicar ante el escepticismo y abandonar la tarea y el esfuerzo por superar los estados de guerra y violencia. Por eso Hoyos sostiene lúcidamente:

La violencia se opone a la idea de paz como deber y a sus procesos como tarea [...] La así llamada violencia del sistema en sus diversas formas, asume sin más una actitud autoritaria y dogmática con respecto a la solución represiva de los conflictos sociales objetivos. De manera simplista se define el descontento, la irritación y la protesta, que lógicamente genera tales conflictos, como violencia que sólo puede ser acallada con las así llamadas fuerzas del orden. Se olvida con esto el principio fundamental que puede animar los procesos de paz y de libertad: estos se conjugan con factores objetivos y factores subjetivos (1984b, pp. 6-8).

Interesa resaltar de aquí la idea de que la paz es, pues, un proceso, y que esta requiere ciertas condiciones objetivas: entre ellas, menciona Hoyos la participación democrática de los ciudadanos en los procesos productivos y de consumo o, para decirlo escuetamente, se requiere justicia y bienestar 
social. Así las cosas, se trata de no tomar la paz a la ligera y pensar "el sentido de la búsqueda de la paz y sus obstáculos", algo que está a la orden del día hoy, cuando la extrema derecha colombiana y sus aliados se esfuerzan por imponer soluciones dogmáticas a las negociaciones de La Habana, sin hacer concesiones y sin pensar en que el proceso mismo es un diálogo de acuerdos y lucha de intereses, pero que todo eso es necesario para lograr una paz social. No se puede claudicar de buenas a primeras ante los retos y los obstáculos que el conflicto nos encara.

Ahora, ¿en este marco, cómo concebía el profesor Hoyos el papel de la Universidad Nacional en los procesos de paz?:

Ciertamente en la actual coyuntura, los procesos de paz y la Universidad se reclaman mutuamente. De la misma manera que la universidad pública debe ser una pieza deliberante y activa en la búsqueda de la paz, la conciencia nacional, orientada a la solución democrática de sus contradicciones, debe reconocer e identificar a la universidad, como lo fue en un pasado no lejano, como lugar privilegiado de dinamización de los factores objetivos del desarrollo y de la formación de la actitud crítica, capaz de orientar ética y políticamente el sentido de tal desarrollo.

Es decir, la universidad debe seguir cumpliendo su función de iluminar la realidad social y, a la vez, la sociedad debe confiar en el papel histórico y en la responsabilidad de la universidad. Las dos cosas deben estar unidas. No se puede privar a la sociedad de los aportes de la academia y a la vez, privar a la academia de cumplir su función para con la sociedad.

Por su parte, el problema de la universidad - su burocratización y cierre de perspectiva, el problema de la universidad colombiana y el tema de la educación públicafue un asunto álgido en las reflexiones de Rafael Gutiérrez Girardot. En sus escritos ya citados se refirió a ellos, así como en su texto "Universidad y sociedad" (publicado el 20 de julio de 1986). El primer problema tiene que ver con la relación entre universidad y sociedad, y sobre sus presupuestos, en especial, en nuestro medio:

Para establecer una relación entre Universidad y sociedad en los países hispánicos, es necesario demostrar a esas sociedades que el saber científico no es comparable con un dogma, que es esencialmente antidogmático; que el provecho inmediato del saber científico no es reglamentable ni determinable por ningún grupo de la sociedad; si no que surge de la libertad de la investigación, de la libertad de buscar caminos nuevos, de descubrir nuevos aspectos por vías que a primera vista no prometen resultados traducibles en términos económicos; que, finalmente, el saber científico y la cultura no son ornamentos, si no el instrumento único para clarificar la vida misma del individuo y de la sociedad, para "cultivarla" $y$, con ello, pacificar y dominar la "violencia" implícita en la sociedad moderna burguesa, esto es, en la sociedad en la que todos son medios de todos para sus propios fines, en la sociedad egoísta (1986, p. 7). 
Una vez aclarado el problema de la misión de la universidad, muy parecido a lo que exponía por la época Guillermo Hoyos, la principal crítica de Gutiérrez apuntó al problema de la "universidad privada o educación privada". Para él, universidad privada era una contradicción en sus términos, pues él, residente y formado en Alemania, solo pudo concebir la educación como un servicio público ofrecido por el Estado y al servicio del Estado y de la comunidad política. Así se expresó al respecto:

El sistema educativo colombiano está determinado por la deformación del principio liberal de la "iniciativa privada", complementando por una abreviada interpretación de la "libertad de enseñanza", que fomenta el egoísmo, profundiza de manera arrogante la "división" de las clases sociales e inculca en los privilegiados - y consecuentemente, en los no privilegiados - la ambición del enriquecimiento fácil y rápido. ¿Cómo han de sorprender la mafia y los demás fenómenos de delincuencia como el secuestro, etcétera, es decir, modos de enriquecerse fácil y rápidamente, si el sistema educativo de la "libertad de enseñanza" y de la "iniciativa privada" enseñan a enriquecerse rápida, fácil y desconsideradamente? (p. 7).

Gutiérrez Girardot culpó a la "formación social aristocrática" impuesta por España siguiendo el modelo del tomismo, y que en América se convirtió en la "casa grande", de implantar una clase aristocrática cuyo único propósito fue impedir la movilidad social y mantener sus privilegios. En esa búsqueda, esa clase usó la universidad privada como instrumento para reproducir las diferencias sociales y evitar las transformaciones democráticas; en pocas palabras, socavó la modernización de la sociedad latinoamericana. Pero más grave aún: esa defensa de intereses es la responsable de la violencia, la desigualdad, el descontento y la ignorancia de estos pueblos. La universidad, pues, se puso al servicio de intereses privados desde su comienzo y feudalizó más la sociedad.

De ahí que la baja calidad de la educación, la instrumentalización miope de la misma, la profesionalización chata, el abuso del principio de la "libertad de cátedra", así como del de "libertad de enseñanza", se hayan pervertido y se hayan puesto al servicio de los intereses mercantiles de esas clases señoriales aristocráticas. Por eso, solo una concepción pública de la universidad permite superar esos escollos y contribuir a la eliminación congénita de la violencia y la desigualdad de estas sociedades. En pocas palabras, como pensaba Hoyos, solo así la universidad contribuye a la paz.

\section{Kant en Colombia}

Uno de los autores que más sirvió a los filósofos colombianos en los años ochenta como excusa para pensar las problemáticas nacionales fue Inmanuel Kant. No solo algunos de los artículos ya reseñados tienen por título la alusión a la famosa "mayoría de edad", sino que Magazín Dominical publicó la traducción de "Respuesta a la pregunta ¿qué es la Ilustración?”, hecha por Rubén Jaramillo Vélez. Por su parte, este mismo autor publicó el texto "Kant y nosotros" (el 23 de diciembre de 1984) y Leonardo Tovar González, "A los 200 años de ¿Qué es la Ilustración? La razón pública hoy" (publicado el 3 de febrero de 1985). En el artículo 
de Jaramillo se aprovecha el llamado del texto de Kant parta criticar la tradición religiosa católica colombiana y mencionar de paso que:

En efecto, no debemos olvidar que la generación nacida por los años en que se combatía al fascismo en Europa o algunos años más tarde, por la época de Guerra fría, alcanzó a percibir que en la historia contemporánea de Colombia hubo un período durante el cual se quiso silenciar a algunos nombres de la humanidad histórica entre nosotros, como el de Kant (y todo lo que asociamos con él), a quien, para dar un ejemplo suficientemente ilustrativo, acusa un teólogo jesuita en un texto de Apologética de enseñanza obligatoria para los cursos de bachillerato por los años sin cuenta de "la Violencia", de ser "el responsable de todos los errores del mundo moderno" (1984d, pp. 6, 7).

El texto de Jaramillo no solo reseña importantes trabajos y eventos que se han hecho en Colombia sobre Kant, sino que de paso le sirve para recordar que "en Colombia, y conviene no olvidarlo, se quiso en un determinado momento eliminar la libertad para la difusión de las ideas, el derecho al libre pensamiento y su libre difusión", es decir, el catolicismo impuso una hegemonía educativa donde se postergó el pensamiento moderno entre nosotros, entre ellos el de Immanuel Kant.

Por su parte, el texto de Leonardo Tovar inicia preguntando si realmente en nuestra época pensamos por nosotros mismos, con autonomía o si, por el contrario, nos mantenemos en la pereza, en la incapacidad de hacerlo delegando en otros esa tarea. Así mismo, su cuestionamiento radical es ¿vivimos en una época ilustrada? El filósofo colombiano resume las posibles respuestas de la siguiente manera:

Para unos la respuesta resulta obvia: la secularización de las conciencias, el progreso científico, el derecho a expresarse garantiza el libre uso de la razón. Para otros incluso la pregunta suena inoficiosa: para qué pensar, si el urgente es actuar. Unos y otros, sin embargo, revelan precisamente que aún no pensamos.

Estas opciones revelan para Tovar que efectivamente no pensamos, debido a la irracionalidad reinante, a la usurpación de la libertad de expresión, al divorcio de la ética de la política, entre otras razones. Y esta ausencia de Ilustración es más notoria en América Latina, donde el colonialismo de tres siglos y el catolicismo frustraron esa posibilidad de pensar por sí mismo, lo cual provocó que el pueblo latinoamericano delegara en otros esa responsabilidad. De ahí que: “[...] en la práctica esto ha conducido a que la gran masa del pueblo siga excluida de las determinaciones públicas, la democracia se limita a ser un mecanismo para que las clases dominantes se repartan el mando y nuestro destino se programe desde los centros internacionales de poder" (Tovar, 1985, p. 10).

Y si bien es cierto que para el caso de América Latina, el colonialismo impidió la Ilustración, eso no exime a este pueblo de luchar por superar esa limitación, el deber de pensar autónomamente.

Por otro lado, si bien antes la tutela del pensar la ejercía la Iglesia, hoy es claro que la ciencia y la técnica se han convertido en una nueva autoridad. Eso hace más urgente el 
uso de la razón, pues a esta "le compete descubrir los fundamentos ideológicos, éticos y políticos sobre los cuales se asienta toda construcción técnico-científica, por objetiva que esta pueda pretenderse". El llamado de Tovar es, entonces, como también lo fue el de su maestro Guillermo Hoyos, a ejercer el "uso público de la razón". Y a pesar de su crítica a la ausencia de un pensar autónomo entre nuestros filósofos, Tovar le asigna tres funciones a la razón en relación con la política:

Siempre la razón debe preservarse como instancia crítica del poder, sin confundirse con el mismo. En concreto, pensamos que a la razón le están asignando tres tareas específicas en relación con la política. La primera, denunciar la falsa razón que sirve al poder de ideología. La segunda, establecer una jerarquía de valores éticos que se constituya en criterio para juzgar el ejercicio político. Y, finalmente, le corresponde concebir utopías o, en lenguaje kantiano, postulados prácticos hacia los cuales el quehacer político, en incesante perfeccionamiento, debe orientarse.

\section{Conclusión}

La presente investigación partió de la pregunta ¿se ocupan los filósofos de las problemáticas de la realidad nacional? El estudio de los artículos de interés filosófico publicados en el Magazín Dominical de El Espectador ofreció luces sobre la cuestión: el levantamiento de archivo arrojó 47 artículos, de los cuales 17 estaban relacionados con problemas que incumbieron a la sociedad colombiana en los años ochenta. El resto son reseñas, panegíricos, notas necrológicas o conmemoraciones.

Tal vez parezca que 17 artículos son pocos para un periodo de diez años, pero eso debe llevar a pensar la lógica misma de la prensa y de sus intereses. Por lo demás, un total de 47 artículos filosóficos indica también que la filosofía, en sí misma, es un producto cultural que presenta cierto interés para la prensa, y muestra un indicador de la presencia que la filosofía tiene en la cultura y en el espacio social, así como del valor social que se le da a la misma.

Por lo demás, al momento de escribir este paper, contamos con un archivo de más de 400 artículos filosóficos publicados en esa misma década en periódicos como El Tiempo, El Colombiano, El Heraldo de Barranquilla y El País. Y puede asegurarse que la ocupación de los filósofos con los problemas nacionales ha sido permanente. A eso debe agregarse -descontando los estudios de Estanislao Zuleta (1997, 2006)y Rubén Sierra Mejía $(2002,2008)$ que se citan como paradigmas en la revista Arcadia - estudios de pensadores que otrora dedicaron parte de su trabajo filosófico a las problemáticas sociales que aquejaban al país: entre ellos, Darío Botero Uribe (1997, 2001), Ramón Pérez Mantilla (2011) o Francisco Posada (2014), o actualmente los estudios de Carlos Rincón o Santiago Castro-Gómez (2009), para solo citar unos pocos.

Todo esto solo prueba que la investigación de Restrepo en la revista Arcadia se quedó corta. Sin embargo, hay que reconocerle que abrió un debate interesante del cual este mismo artículo es eco y que abrió un fructífero campo (inexplorado en Colombia) de investigación que ofrecerá resultados en el 
futuro: las complejas relaciones entre filosofía y prensa, y aportes a la historia intelectual o la historia social de la filosofía (Pachón, 2015).

\section{ReFERENCIAS}

Botero, D. (1997). La crisis política y su incidencia en la institucionalidad colombiana. Revista Politeia, 20, 207-216.

Botero, D. (2001). El círculo dantesco: apuntes para una teoría de la violencia. En $E l$ poder de la filosofía y la filosofía del poder (Tomo II). Bogotá: Universidad Nacional de Colombia.

Castro-Gómez, S. (2009). Tejidos oníricos. Movilidad, capitalismo y biopolítica en Bogotá (1910-1930). Bogotá: Universidad Javeriana.

Cortés Ahumada, E. (15 de julio, 1984). Comentario al texto la filosofía y la provincia.El Espectador, Magazín Dominical, p. 1. Gómez Gómez, A. (29 de julio, 1984). Comentario al texto la filosofía y la provincia.El Espectador, Magazín Dominical, p. 1.

Gutiérrez, R. (20 de julio, 1986). Universidad y sociedad.El Espectador, Magazín Dominical, pp. 6-8.

Gutiérrez, R. (25 de septiembre, 1985). Realidad y heterodoxia de la cultura. El Espectador, Magazín Dominical.

Gutiérrez, R. (17 de enero, 1988). Educación para la mayoría de edad. Diálogo con Rafael Gutiérrez Girardot.El Espectador, Magazín Dominical, pp. 3-9.

Habermas, J. (2010). El discurso filosófico de la modernidad. Buenos Aires: Katz.

Hoyos, G. (3 de julio, 1983). El poder de la universidad es el poder del saber objetivo.El Espectador, Magazín Dominical, p. 5.
Hoyos, G. (17 de junio, 1984a). Respuestas democráticas a una universidad en conflicto. El Espectador, Magazín Dominical. Hoyos, G. (14 de octubre, 1984b). La Universidad Nacional y los procesos de paz.El Espectador, Magazín Dominical, pp. 6-8.

Hoyos, G. (entrevistador) (15 de marzo, 1987). El "mundo de la vida" como fundamento trascendental de todo conocimiento objetivo.El Espectador, Magazín Dominical, pp. 8-9.

Jaramillo, R. (20 de abril, 1980). Sartre: una conciencia moral en la política.El Espectador, Magazín Dominical, p. 5.

Jaramillo, R. (24 de junio, 1984a). Homenaje a los pioneros del pensamiento moderno en Colombia: La filosofía y la provincia El Espectador, Magazín Dominical, p. 14.

Jaramillo, R. (1 de julio, 1984b). La filosofía y la provincia. Segunda parte. El Espectador, Magazín Dominical, pp. 7-9.

Jaramillo, R. (1984c). Respuesta a la pregunta ¿qué es la Ilustración? El Espectador, Magazín Dominical, pp. 6-8.

Jaramillo, R. (23 de diciembre, 1984d). Kant y nosotros El Espectador, Magazín Dominical, p. 7.

Jaramillo (21 de diciembre, 1986). Nota sobre la etiología de la violencia indiscriminada (Magazín Dominical, pp. 20-21). El Espectador.

Jaramillo, R. (2013a). La filosofía y la provincia. Homenaje a los pioneros del pensamiento moderno en Colombia. Revista Aquelarre, 12(25), 203-209.

Jaramillo, R. (2013b). La filosofía y la provincia. Segunda parte, sobre los caminos que ha recorrido la filosofía en Colombia. Aquelarre, 12(25), 211-216.

Martínez Guarín, M. (3 de agosto, 1980). No vamos a tener un Descartes, un 
Hegel o un Kant El Espectador, Magazín Dominical.

Pachón, D. (2015). Estudios sobre el pensamiento filosófico latinoamericano. Bogotá: Desde Abajo.

Pérez, R. (2011). Textos reunidos (Eds. Lisímaco Parra y Luis Hernando Vargas). Bogotá: Universidad Nacional de Colombia.

Posada, F. (2014). Colombia: violencia y subdesarrollo. En C. Rincón (Ed.), Textos reunidos. Bogotá: Universidad Nacional de Colombia.

Restrepo, R. (2011). ¿Dónde están los filósofos? Recuperado el 5 de marzo de 2015, de http://www.revistaarcadia.com/im presa/filosofia/articulo/donde-estan-fi losofos/24577

Sierra, R. (15 de enero, 1984). Acerca de la Filosofía Latinoamericana: lo propio y lo extraño El Espectador, Magazín Dominical, pp. 4-7.
Sierra, R. (2002). Ensayos impopulares. Manizales: Universidad de Caldas.

Sierra, R. (2008). La crisis colombiana. Reflexiones filosóficas. Bogotá: Universidad Nacional de Colombia.

Sierra, R. y Müller, A. (2002). La filosofía y la crisis colombiana. Bogotá: Universidad Nacional, Sociedad Colombiana de Filosofía, Taurus.

Tovar, L. (3 de febrero, 1985). A los 200 años de ¿Qué es la Ilustración? La razón pública hoy. El Espectador, Magazín Dominical.

Valencia, A (Ed.). (1997). Conversaciones con Estanislao Zuleta. Cali: Fundación Estanislao Zuleta.

Zuleta, E. (1997). Conversaciones con Estanislao Zuleta (Ed. Alberto Valencia).Cali: Fundación Estanislao Zuleta.

Zuleta, E. (2006). Educación y democracia. Medellín: Hombre Nuevo, Fundación Estanislao Zuleta. 